\title{
ONREL
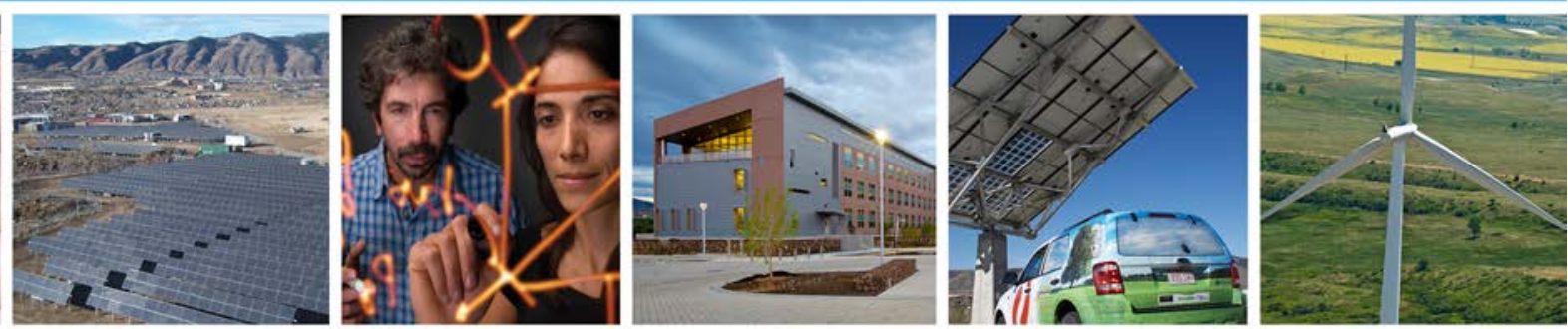

\section{A Framework for Project Development in the Renewable Energy Sector}

Robert Springer

NREL is a national laboratory of the U.S. Department of Energy, Office of Energy Efficiency \& Renewable Energy, operated by the Alliance for Sustainable Energy, LLC. Technical Report

NREL/TP-7A40-57963

February 2013

Contract No. DE-AC36-08G028308 


\section{A Framework for Project Development in the Renewable Energy Sector}

Robert Springer

Prepared under Task No(s). 2900.3014 and WFC5.1000

NREL is a national laboratory of the U.S. Department of Energy, Office of Energy

Efficiency \& Renewable Energy, operated by the Alliance for Sustainable Energy, LLC.

National Renewable Energy Laboratory 15013 Denver West Parkway Golden, Colorado 80401 303-275-3000 • www.nrel.gov
Technical Report

NREL/TP-7A40-57963

February 2013

Contract No. DE-AC36-08G028308 


\section{NOTICE}

This report was prepared as an account of work sponsored by an agency of the United States government. Neither the United States government nor any agency thereof, nor any of their employees, makes any warranty, express or implied, or assumes any legal liability or responsibility for the accuracy, completeness, or usefulness of any information, apparatus, product, or process disclosed, or represents that its use would not infringe privately owned rights. Reference herein to any specific commercial product, process, or service by trade name, trademark, manufacturer, or otherwise does not necessarily constitute or imply its endorsement, recommendation, or favoring by the United States government or any agency thereof. The views and opinions of authors expressed herein do not necessarily state or reflect those of the United States government or any agency thereof.

Available electronically at http://www.osti.gov/bridge

Available for a processing fee to U.S. Department of Energy and its contractors, in paper, from:

U.S. Department of Energy

Office of Scientific and Technical Information

P.O. Box 62

Oak Ridge, TN 37831-0062

phone: 865.576 .8401

fax: 865.576 .5728

email: mailto:reports@adonis.osti.gov

Available for sale to the public, in paper, from:

U.S. Department of Commerce

National Technical Information Service

5285 Port Royal Road

Springfield, VA 22161

phone: 800.553 .6847

fax: 703.605.6900

email: orders@ntis.fedworld.gov

online ordering: http://www.ntis.gov/help/ordermethods.aspx

Cover Photos: (left to right) PIX 16416, PIX 17423, PIX 16560, PIX 17613, PIX 17436, PIX 17721 


\section{Acronyms and Abbreviations}

BEPTC Baseline, Economics, Policy, Technology, Consensus

COD commercial operation date

FC financial close

NEPA National Environmental Policy Act

NPV net present value

NREL National Renewable Energy Laboratory

PPA power purchase agreement

RFP request for proposal

SROPTTC Site, Resource, Off-take, Permits, Technology, Team, Capital 


\section{Table of Contents}

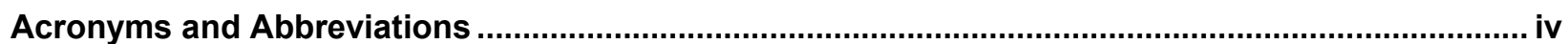

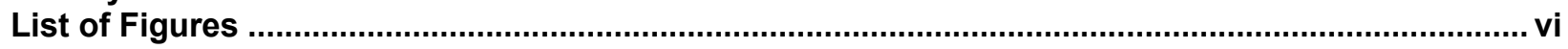

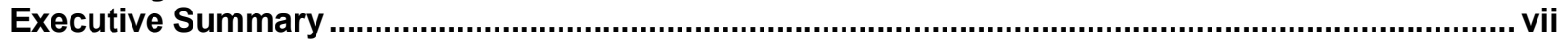

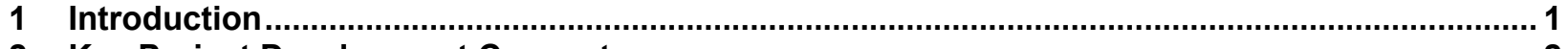

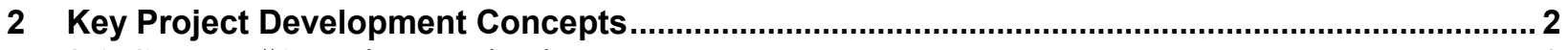

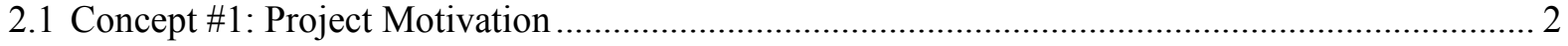

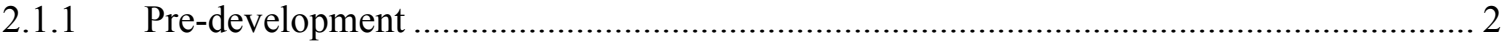

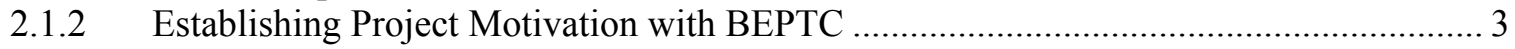

2.2 Concept \#2: Project Development Framework ............................................................................. 5

2.2.1 Seven Essential Elements of Project Development—SROPTTC …................................ 6

2.2.2 Project Development Environment ............................................................................ 7

2.2.3 Iterative Approach/Incremental Investment .............................................................. 9

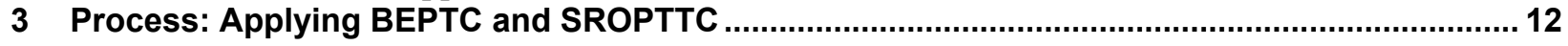

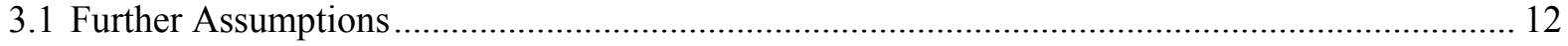

3.2 Defining the Role of Project Host or Sponsor ........................................................................ 12

4 Generic Example of BEPTC and SROPTTC Framework and Process Approach ...................... 14 


\section{List of Figures}

Figure 1. General iterative process concept in project development 5

Figure 2. Three phases of project lifetime and corresponding milestones ..................................... 8

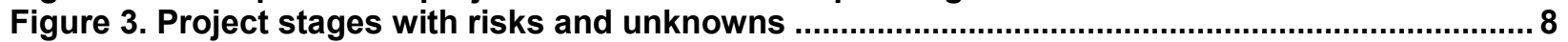

Figure 4. Iterations of SROPTTC framework in the development stage ........................................ 10

Figure 5. Iterations of SROPTTC framework and incremental investment decisions .....................11

Figure 6. BEPTC, SROPTTC, and development phases ................................................................. 13

Figure 7. BEPTC and SROPPTC process diagram with 10 steps ................................................. 14 


\section{Executive Summary}

The development of renewable energy generation projects has become attractive to a variety of energy consumers, installations and large institutions, land and real estate owners, and others (collectively referred to herein as the project "sponsor" or "host") who recognize the economic, environmental, and/or security potential of renewable energy. Whether the aspiration is for projects large or small, and regardless of whether the host will ultimately finance and build the project themselves, each will find it necessary to take on the role of project developer during the early stages of project development.

The size and diversity of potential project sponsors is significant, including but not limited to, the federal government and the military (including all its agencies and departments, facilities and installations); public and private universities and colleges; local and state governments; tribal nations; private and public companies from sole proprietorships to Fortune 500 companies; real estate investment trusts to private individuals; nonprofits and nongovernment organizations. It is rare to have resident professional energy project development experience within the vast majority of these new market participants - many of whom have largely dealt with electrical energy by simply "paying the bill," and now are motivated to consider the relatively radical change of "producing their own," or at least participating in a project in some meaningful way.

The concepts, descriptions, diagrams, and acronyms developed and described herein are meant to provide a contextual framework as well as a systematic, repeatable process to assist a potential project sponsor in understanding and navigating early-stage project development. Professional project developers will recognize these concepts and hold them as intuitive and even obvious, though the fundamentals of this specialized field are rarely written down and defined as they are here.

Project development is primarily viewed as an entrepreneurial activity, subject to significant risks and unknowns while requiring ongoing investment of time, financial, and even political resources toward output that consists of completed projects.

Prior to embarking on the specifics of any particular project, it is essential to gauge the fundamental market characteristics that create the conditions for success and provide sufficient support to generate what we call "project motivation." A motivated project is one that has a clear pathway to success and enough opportunity that it simply cannot be ignored. It is driven by some baseline need or interest in completing the project, the fundamental

Prior to embarking on the specifics of any particular project, it is essential to gauge the fundamental market characteristics that create the conditions for success and provide sufficient support to generate what we call "project motivation." economics of energy in the area, existing policy environment (both internal and external to the project sponsor), and available commercial technologies and renewable resource. This assessment and communication of fundamental project motivation is referred to using the acronym "BEPTC ${ }^{\mathrm{TM} "}$ for Baseline, Economics, Policy, Technology, and Consensus. ${ }^{1}$ Consensus with project stakeholders is ideally built around the four previous characteristics.

\footnotetext{
${ }^{1}$ BEPTC is a trademark of the Alliance for Sustainable Energy, LLC, the operator of NREL.
} 
With project motivation clearly established and communicated using the BEPTC framework, one can seriously approach a specific project with purpose and confidence that the first incremental investment in the project (in time, financial or political capital, etc.) is worthwhile. It is immediately clear that all expenditures are subject to the risk of complete loss, and this risk must be recognized and managed. In response, a key tenet of early-stage development is fatal flaw analysis. To manage development risk, fatal flaws absolutely need to be identified and analyzed quickly and accurately to avoid investment of scarce risk capital into "bad projects" and to conserve these resources. This concept shapes the process of moving a development project forward.

To manage development risk, fatal flaws absolutely need to be identified and analyzed quickly and accurately to avoid investment of scarce risk capital into "bad projects" and to conserve these resources.

Project development now begins in earnest; it is essential to have a clear understanding of the overall context and operating environment, a framework with which to organize and interpret information, an iterative process and fatal flaw analysis that mitigates risk while incrementally moving the project forward, and tools that support and inform decisions, monitor project motivation, and do so in a regular, repeatable, disciplined manner.

NREL has defined the seven core subject areas of renewable projects to be: Site, Resource, Offtake, Permits, Technology, Team, and Capital—and describe each in more depth in the sections that follow. These core areas form the informational framework, and are the source of the acronym "SROPTTC ${ }^{\mathrm{TM}}$," which has come to represent collectively all of the environment, framework, processes, and tools of project development. ${ }^{2}$

The principles and concepts represented by BEPTC and SROPTTC in their entirety are universal to the project development process and essential in successfully managing development risk.

\footnotetext{
${ }^{2}$ SROPTTC is a trademark of the Alliance for Sustainable Energy, LLC, the operator of NREL.
} 


\section{Introduction}

To establish a common understanding and language around the fundamental principles of project development two concepts need to be developed - project motivation and the project development environment. This report details each of these concepts by using the National Renewable Energy Laboratory (NREL)-developed BEPTC and SROPTTC frameworks to highlight and support the predevelopment and development processes and activities each renewable energy project should undergo.

The author is writing this for primary use by an employee or decision-maker in a project host or sponsor role who is considering the pursuit of an on-site renewable energy project of some significant scale. While larger-scale renewable project development is most obviously in need of an intensive development management scheme, the general principles and practices are applicable on projects of any size.

The first concept is project motivation - a motivated project is one that has a strong basis to come to fruition and is built on economics and risks that are acceptable to all parties; supportive policies and an execution pathway; and project "bankability." The five essential areas for strong project motivation-Baseline, Economics, Policy, Technology, and Consensus - are referred to as BEPTC.

The second concept is developing a contextual framework and mapping an established, repeatable, disciplined process for project development that is consistent with professional commercial practices. The seven essential areas for strong project development-Site, Resource, Off-take, Permits, Technology, Team, and Capital—are referred to as SROPTTC.

Section 2 details each of the key concepts of project motivation and project development in more detail.

With the general concepts of project motivation and project development introduced, project hosts and/or sponsors need to take the time to consider the concepts in action and begin thinking about how to apply them. Section 3 provides details and examples for applying the BEPTC and SROPTTC concepts. 


\section{Key Project Development Concepts}

The two major concepts to establish a common understanding and language around the fundamental principles of project development are project motivation and the project development environment.

A motivated project is one that has a strong basis to come to fruition and is built on economics and risks that are acceptable to both parties, and includes supportive policies, an execution pathway, and project "bankability."

The second concept is a framework and mapping of an established, repeatable, disciplined process for project development that is consistent with professional commercial practices. These concepts are discussed below in greater detail and address the high-level steps for government agencies and private companies (together known as a "project host") to consider when approaching renewable energy project development.

\subsection{Concept \#1: Project Motivation}

What we call "project motivation" is created through strong fundamentals and provides the source of commitment and clarity of purpose that are necessary to both generate the resources required to develop a project and the perseverance required to make it happen. Without properly establishing project motivation, the necessary resources (funding and skilled human resources) will not be brought to bear. A fundamental, but common, mistake in early-stage project development is to jump to technical or financial details prior to building consensus among project stakeholders and establishing project motivation that is sufficient to maintain a sustained effort backed by common purpose.

\subsubsection{Pre-development}

As described earlier, to achieve its goals, the project host or sponsor is likely to engage a professional renewable energy installer or provider, and must be perceived as an attractive transaction partner to the renewable project developer community to mobilize the private investment necessary to move projects forward.

Given the state of the industry and the current financing environment, there is a limited volume of project development risk capital and project finance capital available in the market (this is always the case, but markets are more restrictive in 2011). The entire energy market is competing for these same limited resources. Projects that are presented to the private sector with unacceptable levels of uncertainty stemming from undefined development risk, or fundamental project characteristics that are not commercially acceptable, will not likely proceed any further.

To overcome the challenges of the competitive market, a project should go through a "predevelopment" process in which the project is qualified in accordance with industry (and financier) standards, thereby decreasing early-stage development risk. A properly executed predevelopment program will produce a very well-defined, attractive development opportunity that garners multiple competitive bidders willing to fund the remaining development activity and shoulder the remaining risks. Establishing the motivation and key factors for a project's success is essential to generate the resources and expertise necessary to execute the project during this predevelopment stage. 
Any entity, public or private, that is the sponsor, host, or contractual counterparty for the project needs to function as an early-stage project developer during the predevelopment stage, either through direct resources or in conjunction with the owner's representative role. This effort will require financial and human resources and expertise, and may typically amount to $1 \%$ to $2 \%$ of the total project costs (including hard and soft project costs).

\subsubsection{Establishing Project Motivation with BEPTC}

In simple terms, the five essential areas for strong project motivation listed below have been referred to using the acronym BEPTC, building off of the titles of Baseline, Economics, Policy, Technology, and Consensus.

Although there is no particular magic in the acronym itself, it is used to refer to the collection of activities, essential data, and ultimate outcome of establishing a strong basis for project motivation.

When the private sector engages in project development activities, "project motivation" is established using the principles of BEPTC but are referred to with the commercial term "market study." As for-profit commercial enterprises, these companies invest in up-front studies to identify areas of opportunity in various markets, and then use the motivation and knowledge generated from that analysis to pursue project development activity (meaning investing further resources).

We will use this convention throughout this document when referring to establishing project motivation.

Baseline. First, state the fundamental reason(s) the project is necessary or desired. An objective analysis of energy supply reality and/or clear statement of specific goals are typically where this baseline can be found. The simpler the statement is the more powerful and useful it is. A colorful example for the state of Hawaii might be, "For energy and economic security, we can no longer rely on burning tankers of foreign sourced petroleum on a month to month basis." In this single statement, the motivation is clearly articulated and very hard to get away from - this type of clarity captured in one sentence provides a grounded, fundamental statement of purpose. A general rule of thumb would be to define the baseline within one or two sentences.

Economics. A reasonable and objective analysis of fundamental energy economics must be established both in terms of the total costs of acquiring energy from existing sources (selfgenerated or utility based) and from the proposed sources as comparison. If there are negative economic differences between the existing and proposed sources, even just in the initial years of operation - and those differences are not acknowledged and dealt with upfront - the project will suffer later in the process. Relying on the project development process and/or a financing miracle to overcome the economics will rarely, if ever, result in success. As a rule of thumb, if a project does not have $20 \%$ to $30 \%$ of margin above general cost estimates to accommodate profit and uncertainty at the concept stage it very well may not have supportive economics. Should this be the case, mitigation steps or a strategy to alleviate this must be established. 
Policy. Federal, state, local, and regulatory policy environments must be examined for barriers and addressed prior to expending significant resources pursuing a project. The project and steps taken to mitigate, remove, or deal with these policies to create the conditions for success are imperative. Without identifying policy issues and, at a minimum, forming strategies and tactics to overcome these challenges, investing resources in a project is at best risky and needs to be acknowledged as such, and at worst, ill-advised and likely will be lost altogether.

Technology. Fundamental technology assessments and analysis may be the most straightforward part of establishing project motivation. Resource assessments that characterize the renewable resource for a specific site might be available from a simple desktop study. Assessing commercial technologies, reliability, and bankability may require more, but still relatively minimal, effort. Once a portfolio of available resources and commercial conversion technologies has been established, it is necessary to defend against nonbankable or unrealistic early-stage technologies from confusing or distracting the project leadership or stakeholders from making decisions and taking action.

Consensus. Building off of the final point of the Technology section above, communication and consensus-building among stakeholders of a project is vital. To generate buy-in, a common understanding of the project fundamentals, and a unification of purpose is essential; the project development process will involve many parties' input, investment, and possibly compromise. Without consensus and communication efforts, precious resources will not be made available, and stakeholders can become adversaries to the project before it even begins - the stage when a project is most vulnerable.

With project motivation established and defined using the principles of BEPTC, it is likely very clear that there is reason to pursue the identification and development of a specific project or projects, and because the motivation is defined and understood, support will be available to undertake this effort. Specific technologies (and therefore renewable resources) have been identified; policies examined or changed to create a pathway to execute projects, stakeholders are engaged and supportive of these details and there is a fundamental understanding of what drives the organization to pursue energy development.

It is typical to measure or score project motivation in financial terms - net present value (NPV) is used commonly by industry. The theory is that all aspects of the project can be represented in financial terms and, through the use of a pro forma, can be measured and tracked over time. This is not entirely true in all circumstances, but it does generally provide a consistent, rolled up measure of relative project motivation.

The process of developing a project from concept to completion is both iterative (see Figure 1) and cumulative as additional information is acquired and unknowns are eliminated. The confidence level associated with project motivation increases as incremental investments are made and the project becomes more defined. In general, more motivation (higher NPV) is needed at the earliest stages of development to compensate for uncertainty.

Project development can now commence in earnest, and as individual opportunities are identified the use of the SROPTTC framework (introduced next), recognition of the development environment, including risk profiles, and activation of a process that mitigates risk can begin. All 
of this is taking place with the support of specific tools, like pro formas and development checklists.

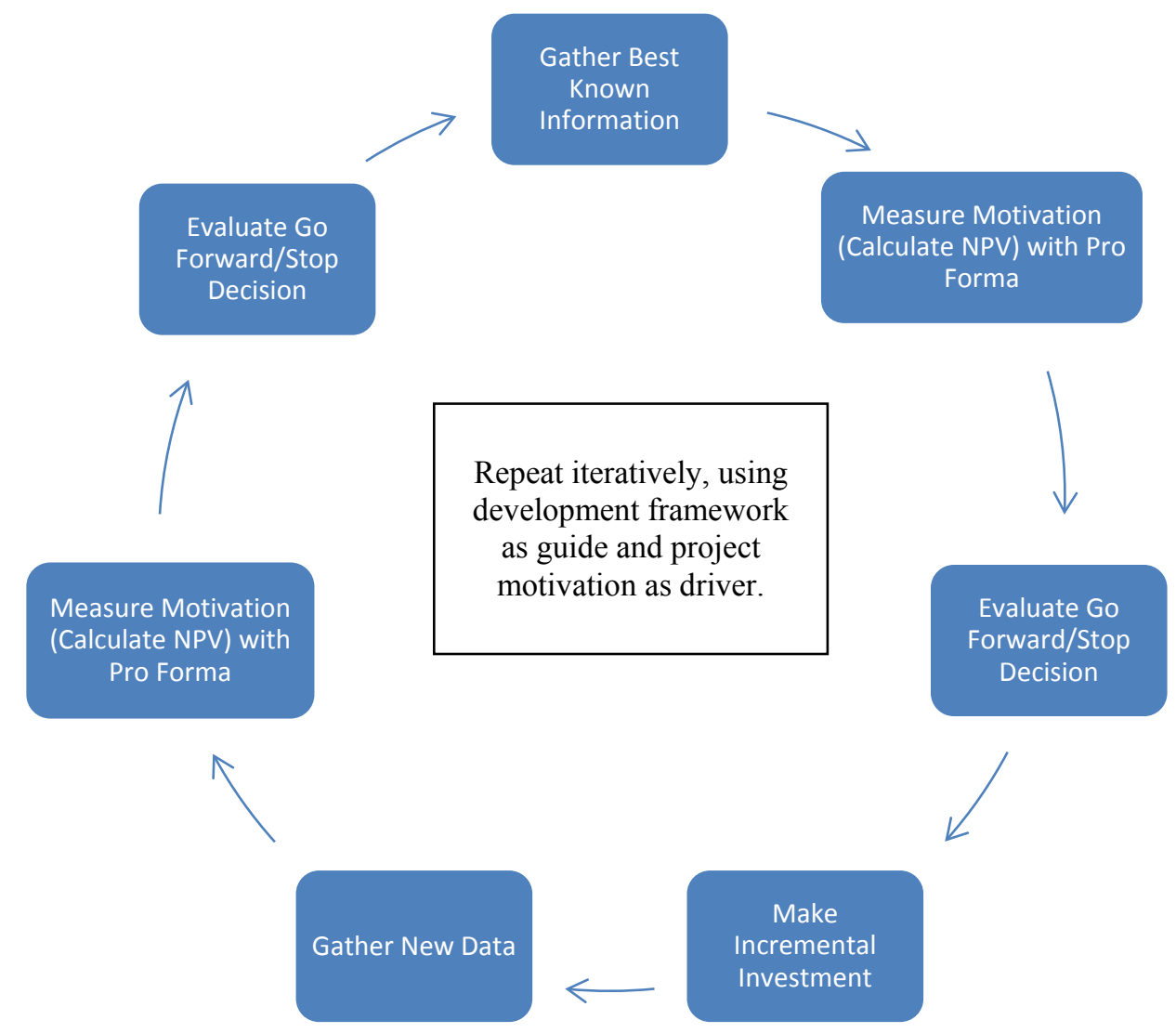

Figure 1. General iterative process concept in project development

\subsection{Concept \#2: Project Development Framework}

The second key concept we seek to introduce is a framework that provides the basis of an accepted approach to establish a regular, repeatable, documented project development methodology that has its foundation in commercial project development practice. One of the important drivers of this methodology is the risk profile of the development process, which differs from the other major stages of project evolution. This is designed to establish a common understanding of the process over time and the ability to map project progress, and provides context to decision makers.

It is especially important to reiterate that the early project development steps are conducted and led by the sponsoring entity or project host. The risks of early-stage development may not be obvious, and need to be well-understood - this is the driver of using the SROPTTC framework and processes - to manage development risk. Without explicit acknowledgment and management of this risk, poorly executed early-stage development activity and investment could lead to either the misguided execution of poorly performing projects or the unnecessary loss of investment that could be avoided and minimized early in the development process. 


\subsubsection{Seven Essential Elements of Project Development-SROPTTC}

To establish a framework, we start by introducing the seven essential elements of the project development process and activity. The seven areas NREL developed and defined are referred to as SROPTTC building off the titles of Site, Resource, Off-take, Permits, Technology, Team, and Capital.

As with BEPTC, anyone can argue about the specific words and labels, but ultimately NREL maintains that the principles represented here are unavoidable, built from accepted business practices and professional experience in private project development investment and execution. It is on this framework of information and activity embodied in the seven elements that we hang the process, systems, and tools of project development, and will use as a convention throughout this document when referring to the project development process.

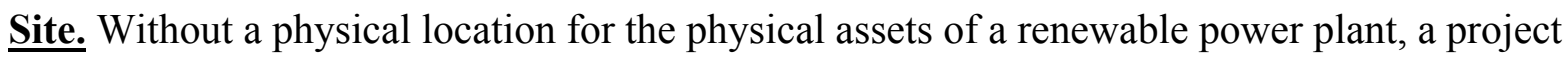
will not happen. Beyond this simplistic idea comes the technical aspect of what financeable site control entails including, but not limited to, conveyed property rights, legal definition (through legal descriptions and/or accredited surveys), assignability (relating to financing requirements), length of tenure, terms and conditions, default and cure clauses, and other fundamental contracting issues. Furthermore, there are the obvious physical constraints of a site, which include but are not limited to: slope, vegetation, soil conditions, infrastructure, access, associated resource impacts, etc. All of these items must be considered in the context of site planning, highest and best use, and conflicting or competitive uses for the land that may relate to the mission of the facility itself. The level of detail necessary in all of these areas is on a sliding scale over time - starting at a broad level and ending with highly detailed information.

Resource. The renewable resource being considered for the project needs to be characterized and understood at a level of detail and confidence appropriate to the stage of development the project has progressed to. For early feasibility assessments, a general assessment of resource availability is used, whereas for investment grade studies, highly detailed hourly or subhourly data and analysis may be used to establish and support resource availability, quality, and characteristics within a tight range of certainty. Developers may use maps generated by NREL for early-stage resource assessment, moving to technical correlation using 12 months of on-site data with long-term computer modeling of satellite-based datasets.

Off-take. The buyer of both the energy and any other characteristics of output (like renewable energy credits) must be established and ultimately secured by contract, often a power purchase agreement (PPA) or other similar contracting method. Because of the complexities of financing and building renewable projects, we use the general term "offtake." This term implies that there is an economic and executable agreement by the project parties, and that it is ultimately confirmed by written contract. If the project is in a regulated market, approval by a public utilities commission or other body may also be required. There are many details to off-take, many pathways to follow to a PPA agreement, and many financing implications along the way to generating a fully executed off-take contract. Embedded in this subject area is also the issues of transmission and interconnection, relating to the direct and ancillary infrastructure and agreements required to "get to market." Confirming and ultimately consummating the financial relationships contemplated by the 
original project motivation and concept in a PPA and related documents is a critical milestone in the process of project development.

Site, Resource, and $\boldsymbol{O} f f$-take are the core elements of project development. Together they create value that promotes further investment. Securing these three elements by contract is a significant milestone for a project developer.

Permits. This encompasses all permits necessary for project construction and operation, including all federal requirements related to environmental regulations in the National Environmental Policy Act's (NEPA) Environmental Assessment or Environmental Impact Study requirements; and state and local jurisdictional permits, including local entitlements, electrical contracting permits, and building permits. Generally, without strong development of the Site, Resource, and Off-take elements, significant investment is not made in permits. That said, it is an important element to understand from both a feasibility and risk standpoint - if a project has a high hurdle for permitting, and therefore includes significant permit or policy risks, it needs to be understood and executed with that knowledge in mind. NEPA risk, in the case of a federal project in particular, is generally unacceptable for renewable energy developers who may turn instead to the nonfederal market opportunities. A strategy to mitigate NEPA risk for the development community may therefore be essential for renewable energy project successes in the federal sector.

Technology. The technology area inherits the going-in assumption of technology developed in the BEPTC framework (i.e., this will be a photovoltaic, wind, or biomass project) and migrates to the investment in and engineering design, equipment selection, and procurement activities. Common stages of engineering design include conceptual and design development, and construction documents with full specifications for bid and contract procurement. All of this activity requires investment into the design process and evolves incrementally as further investment is deemed warranted for the project.

Team. Assembly of a fully qualified team that address all business, technical, financial, legal, and operational aspects of a renewable energy project is an essential final step prior to raising debt, equity, and incentive/grant program capital. Proven experience and capability are key elements to most investment decisions by qualified investors.

Capital. With all other elements in place, Site, Resource, Off-take, Permits, Technology, and Team, the project will attract the financial resources necessary for final development, construction, commissioning, and initial operations (through stabilized cash flows after the commercial operation date [COD]).. This is the final step as described in this framework, but it is important to reiterate that capital requirements do not begin at construction but are engaged at incremental points along the development process. Here, capital refers to both the predevelopment and development stages, and then in a financial closing that includes the financing required through construction and initial operations.

\subsubsection{Project Development Environment}

Taking SROPTTC into a time-based process environment is helpful to see how to use the framework to organize and execute a disciplined project development process. First, for context, we'll establish the three distinct phases of activity for projects, and the milestones that separate and define them. As shown in Figure 2, a project goes through a development stage, project finance (construction) stage, and an asset stage. 


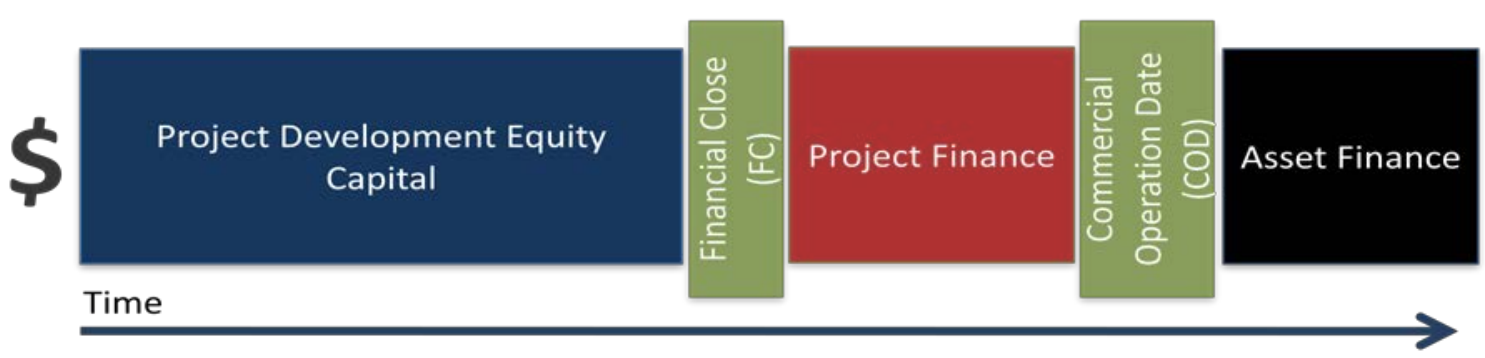

Figure 2. Three phases of project lifetime and corresponding milestones

During each stage, different capital is employed due to the nature of the risk/return relationship in financial terms and the capital market segments that have an appetite for particular investment types and tenure. Between the stages are two key milestones-first is financial close (FC), where project financing transitions between development risk capital and project finance. Once the project has been constructed and is operating, it has reached its COD and enters the final stage as an asset. From this time forward, it can be traded and financed using asset finance.

It is the difference in risk profile that begins to distinguish the capital involved in these stages, and therefore also distinguishes the methodology of dealing with risks in each of the three areas of a project's life. The major sources of risks in projects are the "unknowns." The level of unknowns in a project are very high in the early development stages of the project (far left of Figure 2), when compared to the far right side when the project is an operating asset with known characteristics and a proven track record. It is easy to assume that risk follows the same pattern - generally declining left to right over time as a project matures. This is a key element of departure, a nuance to the development process and milestones as described in Figure 2-in fact, risk begins to take on a different profile when mapped over time, as shown in Figure 3.

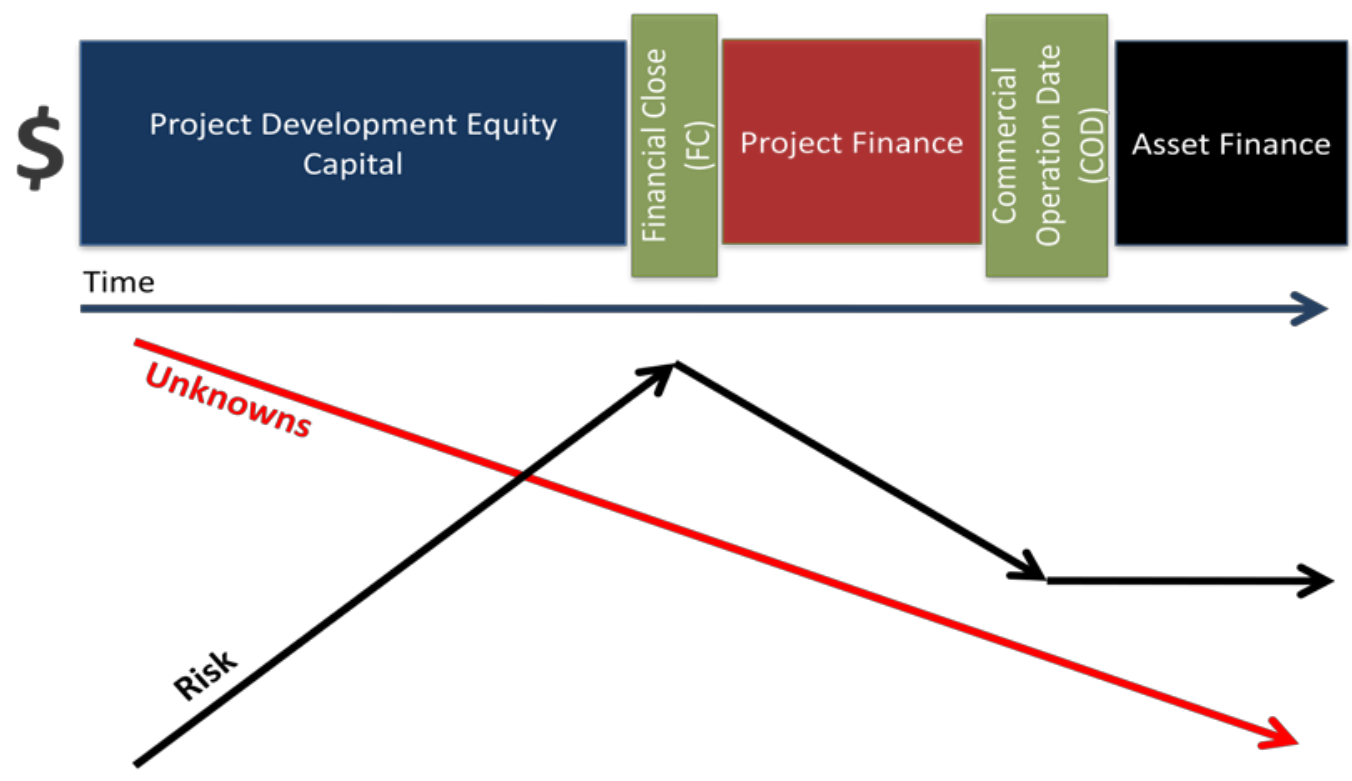

Figure 3. Project stages with risks and unknowns

Our intuition around risk and unknowns is not served during the development stage, resulting in the counter-intuitive adverse relationship between risk and unknowns as shown in Figure 3 . The primary cause of this disconnect is that the capital investment in the development process is 
made incrementally and cannot earn a return until FC. All funds invested in the development process have to be considered at risk for total loss; therefore the risk profile ratchets up as this investment is made. In contrast, investment in the project finance phase is made in full, or at least committed, at the financial closing milestone. It is accepted as a condition precedent that all risks are well identified, allocated to, and mitigated by project participants at this point in the process. The unique risk profile of the development costs drives the process methodology, which we will discuss next.

\subsubsection{Iterative Approach/Incremental Investment}

The nature of the risk profile for predevelopment and development investments drives an incremental, iterative approach to project development. Using the framework subject areas of SROPTTC, a project is put through an analysis of known and available information supported by necessary and reasonable assumptions. The nature of this work is a fatal-flaw analysis that seeks to determine fatal flaws and identify areas of significant risks to project completion.

The first iteration consists of confirming and documenting what is known in the framework elements of SROPTTC, and then casting that information in a format that can be used to inform the decision of whether to invest further in the project or stop in favor of alternatives that deliver the same or similar results identified in the BEPTC analysis.

Two core tools are typically used in support this analysis - a development checklist and a development pro forma. The development checklist provides a basis of issues to be checked and resolved, and typically evolves and grows with experience (such that new items are added from lessons learned on each project). The pro forma is used to begin to cast the information and data collected and organized within the SROPTTC framework in financial terms, which can then be used to measure and evaluate the project's attractiveness throughout the development process relative to both project motivation and risk. These tools will be discussed in further detail later in this document.

Turning to Figure 4, we focus on the development stage of the project, and add the SROPTTC framework running left to right over time representing the development of greater amounts of detail (and less unknowns) over time as the project is fully developed. Using the SROPTTC framework and the help of a development checklist and experienced personnel, information is aggregated and captured through a financial representation in a pro forma. 


\section{Project Development Equity Capital}

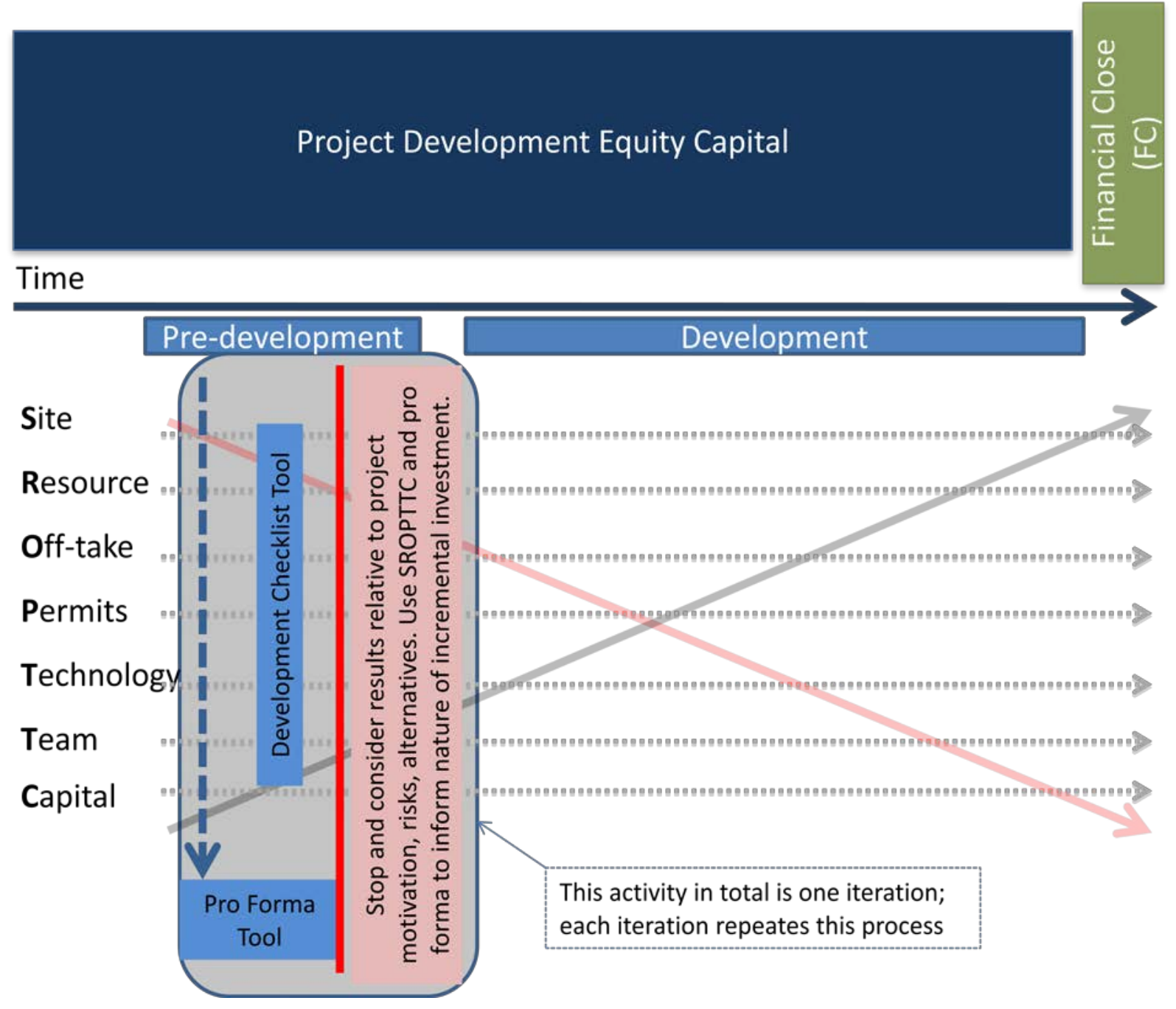

Figure 4. Iterations of SROPTTC framework in the development stage

Figure 4 shows the major elements of each successive iteration: investment in the generation and definition of key information and data within the SROPTTC framework. This is done using the development checklist as a guide, the resulting pro forma as a consistent point of measure, and an ever-present fatal flaw assessment of what was learned relative to the risks and reward (project motivation) of the project. Each assessment asks the questions:

- Has a potential fatal flaw been identified? If so, should the project be stopped, or would an acceptable investment potentially mitigate or eliminate the flaw?

- Have major risk areas been identified? If so, how can these risks be better quantified and mitigated? What are the costs allocated to mitigate risks, and are they sufficient?

- Where are the unknowns, and how can they be further mitigated?

- Where would the next dollar of investment in time and/or money be best applied to reduce unknowns, mitigate risks, and develop key information? 
Should the project still be considered viable and worth pursuing further, the process is to evaluate the key areas of incremental investment that will most efficiently increase the chances of success - or limit the downside of failure through early identification of fatal flaws to end investment in a project with poor chances of success. This process is repeated iteratively, making incremental investments and judgments amounting to "Go Forward/Stop" decisions between each iteration. The result is a series of incremental investments followed by assessments that systematically evaluate the information organized within the SROPTTC framework subject areas, define key parameters of the project, and drive unknowns from the system (see Figure 5).
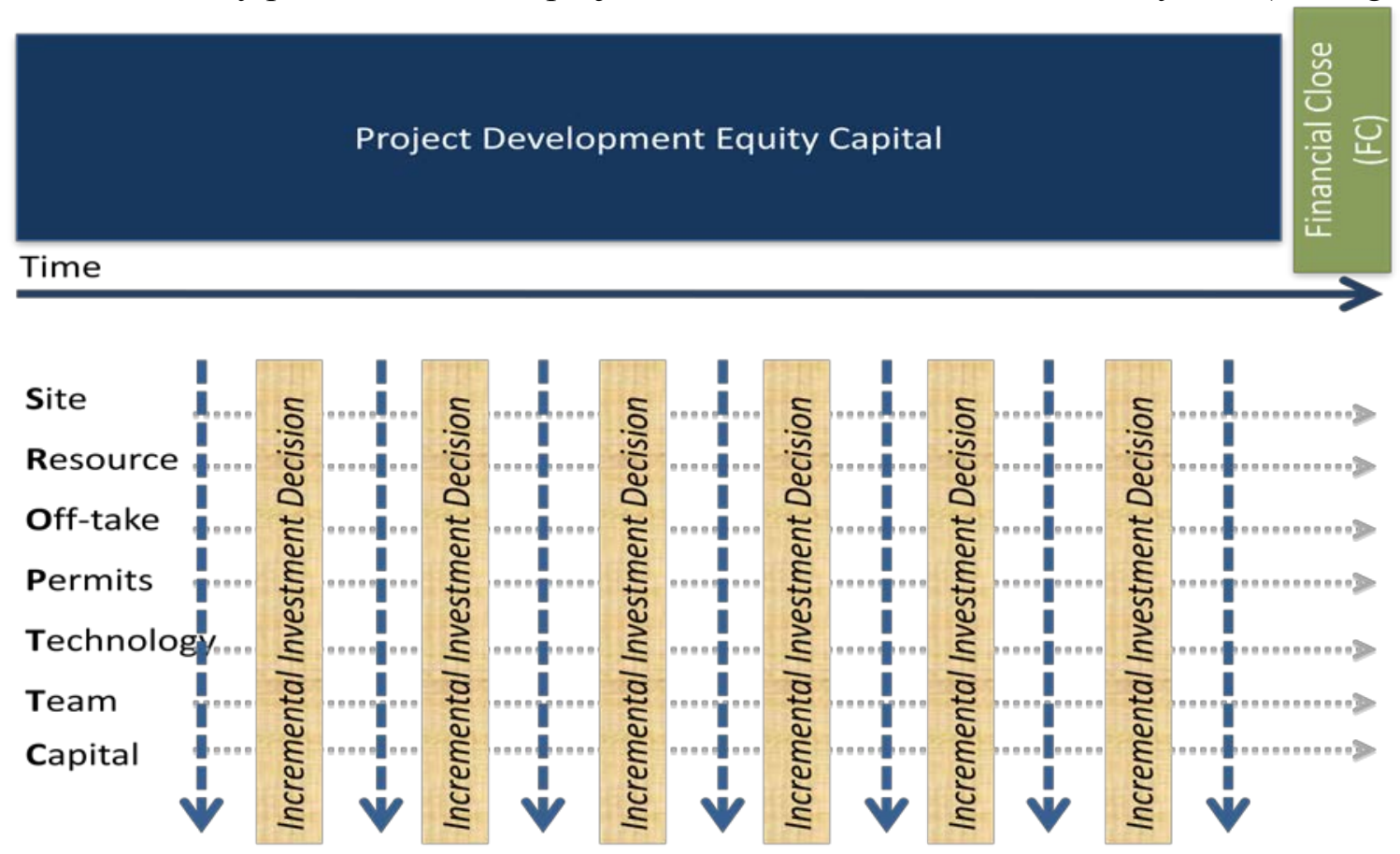

Iteration Iteration Iteration Iteration Iteration Iteration Iteration

Figure 5. Iterations of SROPTTC framework and incremental investment decisions 


\section{Process: Applying BEPTC and SROPTTC}

With the general concepts of project motivation and our project development framework introduced, it is time to consider these in action and begin thinking how to apply them. Because of the many stakeholders and roles involved, it is a complex system; a simple, linear process is not entirely accurate - the system is complex and variable enough that it cannot be described in infinite detail without becoming cumbersome and unusable. We aim to take a simplified but balanced approach and introduce the reader to the fundamentals in a variety of formats, then build on those fundamentals and illustrate with a project example.

\subsection{Further Assumptions}

As noted in Section 1, the information in this report is primarily for use by an employee or decision-maker acting for a project host or sponsor that is considering the pursuit of an on-site renewable energy project of some significant scale.

It is our assumption in this section that the project is expected to be funded by private financing, using one or more finance mechanisms prevalent in the renewable energy market: PPA, or in federal or other government applications such as Energy Savings Performance Contracts, Utility Energy Service Contracts, Enhanced Use Lease, or others. It is assumed that the procurement of the project will occur through some form of competitive bidding framework, like a request for proposal (RFP) format (which we will use here as a proxy for the process of transferring the primary development risk from the sponsor or host to a third party).

All of these stated assumptions are made to simplify this discussion, and the general process described applies to the many variations on this theme that are available. Engaging with a project development expert will help translate these elements for a given situation.

\subsection{Defining the Role of Project Host or Sponsor}

As discussed earlier, to gain the benefit of third-party investment into renewable projects on public or private sites, the project must present an attractive opportunity to the renewable energy development and investment community. To do so, we maintain that only a well-defined project that has gone through a predevelopment process that mirrors the commercial development process should be presented for action through an RFP or other procurement methodology. Thus, we have developed the BEPTC and SROPTTC frameworks, which are built off of professional project development business practices, to provide guidance and a reference point for those leading the process.

Predevelopment is made up of stages that are described many ways; we use due diligence, feasibility, and conceptual project development stages - followed by a fully engaged project development and investment effort in a highly qualified and well-defined opportunity. It represents the earliest stages of development, and the most risky investment for third-party developers. By taking on the role of the project developer in the predevelopment process, the project host or sponsor effectively de-risks the project opportunity, providing a better-defined and more attractive opportunity to the market.

In Figure 6, we introduce BEPTC as well as more detailed descriptions of development phases to our series of process diagrams, bringing more clarity to the overall process. To this we will add a 
representation of the host or sponsor's role in transitioning to the renewable developer through an RFP process.
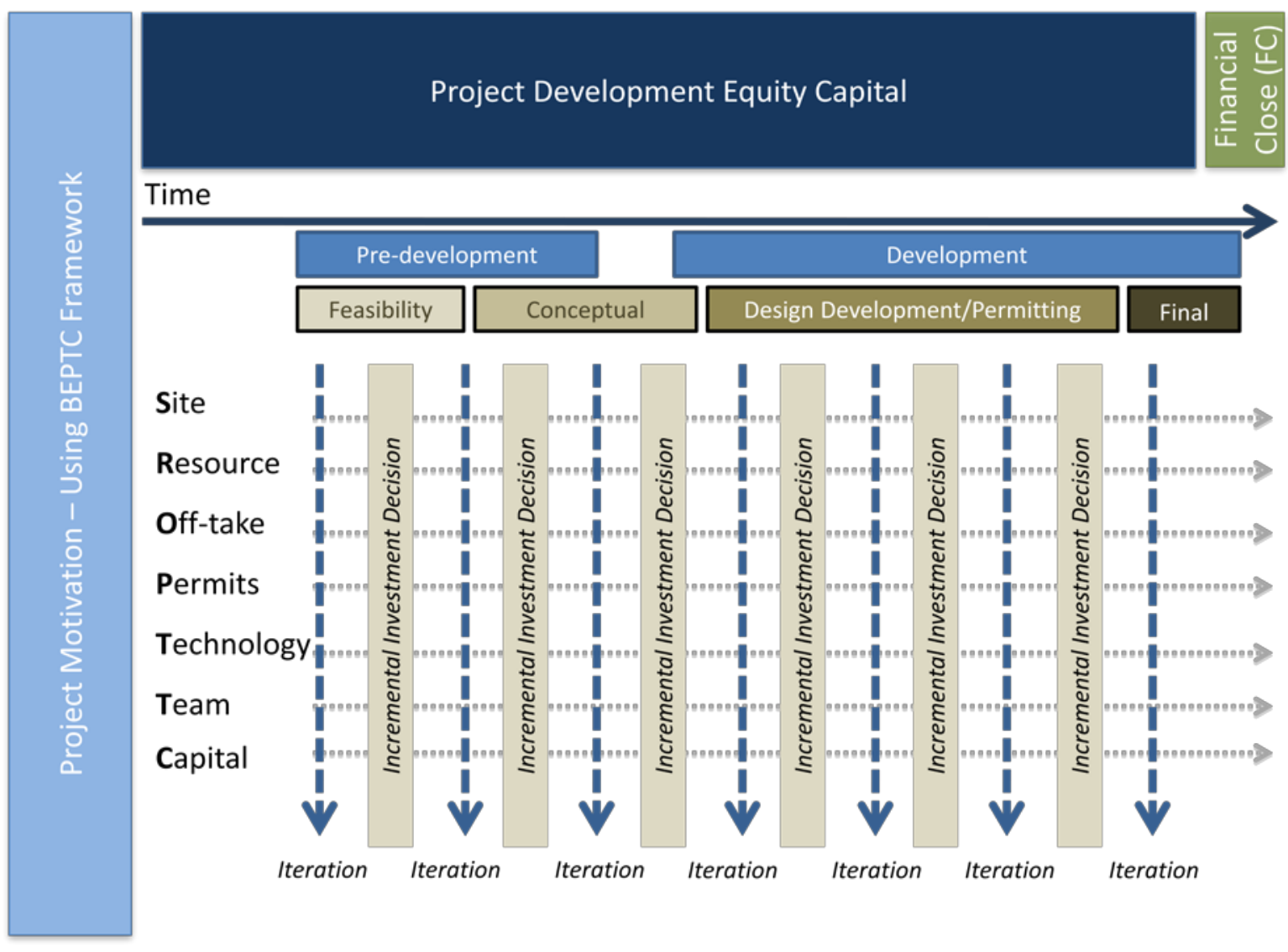

Figure 6. BEPTC, SROPTTC, and development phases

The question of roles and timing of the transition from host to project developer investment in a project opportunity does not have a simple, universal answer. There will be unique aspects to most projects in the near future that will drive the specifics of that decision.

We offer the general guidance in Figure 6, which shows a transition point within the conceptual project development stage - with the host or sponsor developing project motivation to mobilize the resources required to get through the predevelopment stage, as well as ongoing participation as a transaction counter-party after the RFP date (an RFP being used here as a proxy for a procurement process). This acknowledges that an RFP does not define the end of the host or sponsor role - ongoing resources and expertise will be necessary to provide a strong and effective partner throughout the remaining development process. 


\section{Generic Example of BEPTC and SROPTTC Framework and Process Approach}

As shown in Figure 7 below, it is possible to conceptualize a 10-step process to describe the major steps suggested by our BEPTC and SROPTTC framework approach. Note that when considering a large-scale renewable energy project using this outline of steps, experienced assistance and proven tools are essential to navigate the pitfalls of process and to inform key decisions throughout.

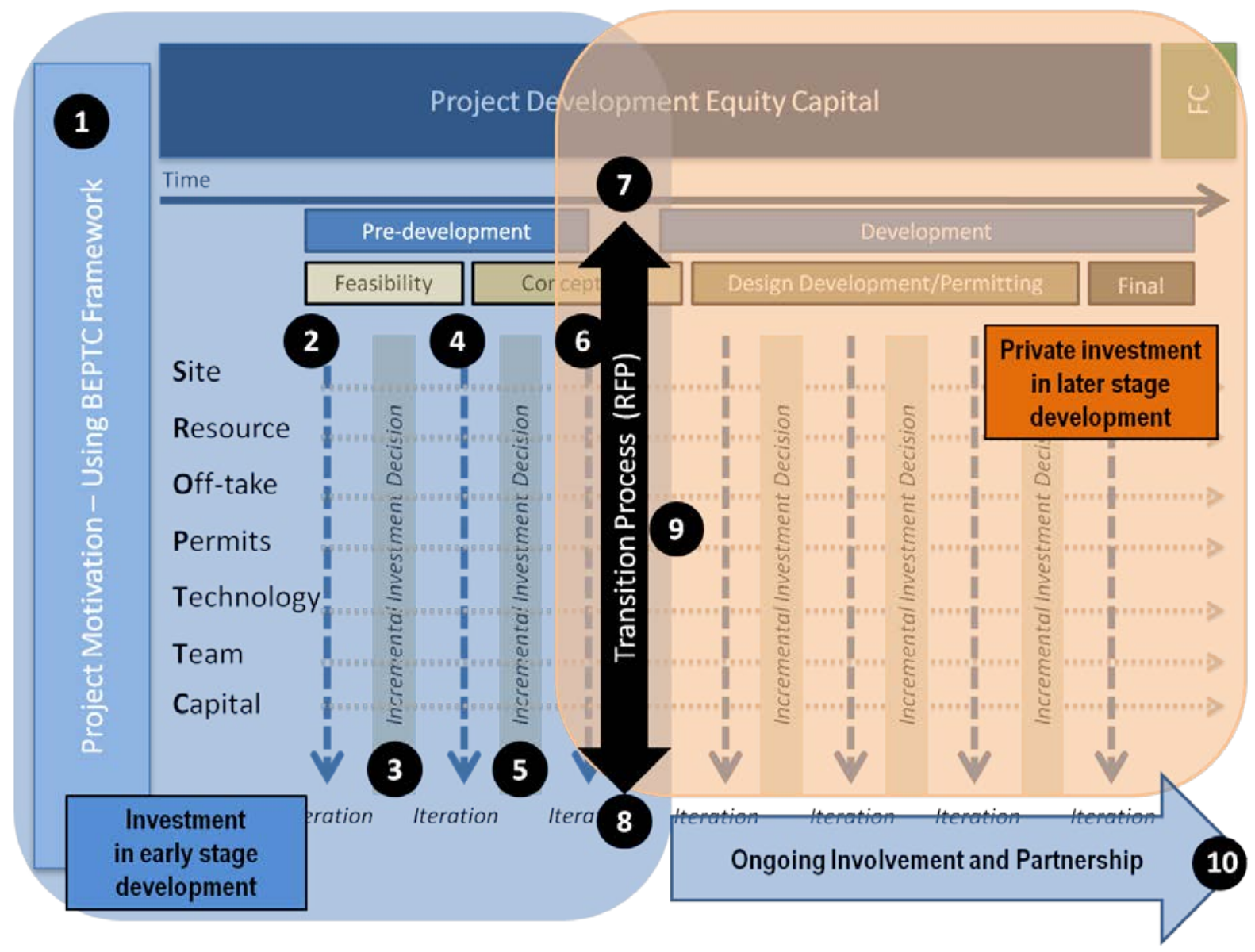

Figure 7. BEPTC and SROPPTC process diagram with 10 steps

Step 1: Establish project motivation using BEPTC.

Project motivation is essential to establish a firm foundation of purpose that is based on agreedupon fundamentals and will generate the commitment of resources necessary to attract private investment, both project development capital and project finance capital, into renewable energy projects.

Step 2: Initial project assessment for fatal flaws using SROPTTC framework as a guide.

Concentrating on the issues of Site, Resource, and Off-take, and the related issue of economics and bankability, conduct a high-level assessment of the seven SROPTTC subject areas with the 
purpose of identifying fatal flaws, significant areas of risk, and gaps of information. Engage experienced advisors to guide this process using established tools and professional opinion.

Step 3: Incremental investment decision.

With the assessment conducted using the SROPTTC framework, determine what has been learned and, using the output of a pro forma economic analysis, determine if sufficient motivation exists to continue forward with an incremental investment. If so, direct investments to most efficiently take the project forward to the next decision point.

Step 4: Further predevelopment work deploying investment from Step 3, using SROPTTC as a guide.

Invest time and resources to more fully develop information within the SROPTTC framework, concentrating on the incremental investment suggested by the prior iteration. Use SROPTTC to concentrate on verifying Site, Resource, and Off-take elements while continually seeking fatal flaws in Permit, Technology, Team, and Capital, and pursuing mitigating actions for risks across the project.

Step 5: Incremental investment decision.

With the second assessment conducted using the SROPTTC framework, determine what has been learned and, using the output of a pro forma economic analysis, determine if sufficient motivation exists to continue forward with an incremental investment. At this point, it should be clear that Site conditions, Resource, and $\mathbf{O f f}$-take arrangements are bankable and economic.

Step 6: Further predevelopment work deploying investment from Step 5, using SROPTTC as a guide.

The result of this iteration should be a project plan that addresses and defines the known elements of SROPTTC in preparation for delivery to the private sector in a potential procurement or RFP process. References and documentation of the existing status should be in hand, sufficient for developers to assess remaining risks and development activity, as well as a clear and defined pathway to final approval and contract execution.

Step 7: Go Forward/Stop on RFP process initiation.

Based on assessment of the output of Step 6, a Go Forward/Stop decision should be made. The project needs to be judged to include acceptable and financeable risks by the private sector development community, using industry interaction or advisory as a reference to establish criteria.

Step 8: Pursue private partner through RFP process, communicating SROPTTC fundamentals.

Conduct a competitive procurement of the project, acknowledging the continued development process and agreement to work as an active transaction partner to pursue project completion. 
Step 9: Select and negotiate with awardee.

Qualify, select, negotiate, and award the opportunity.

Step 10: Ongoing partnership with private sector developer as transaction counterparty.

Actively participate, with the support of ongoing resources, the development of the project in conjunction with the selected private sector development team to carry the project forward into a completed deal, mutually beneficial to both parties, and/or other project participants or key stakeholders (such as the local utility). 